\title{
BIOENERGETICS OF THE CAMEL CRICKET CEUTHOPHILUS STYGIUS
}

\author{
Eugene H. Studier, Kathleen H. Lavoie, William D. Wares II and Julie A. M. LinN* \\ Department of Biology, University of Michigan-Flint, Flint, Michigan 48503, U.S.A.
}

(Received 29 April 1986)

\begin{abstract}
In early summer, camel crickets in Mammoth Cave National Park exhibit a sex-specific relationship between crop-empty live weight and hind femur length.

2. They also exhibit curvilinear long-term weight loss patterns averaging 2.67 and $3.13 \mathrm{mg} / \mathrm{hr}$ for females and males, respectively, and caloric assimilation efficiencies of 65.6 and $70.5 \%$ for females and males, respectively.
\end{abstract}

\section{INTRODUCTION}

Many caves, including the limestone caves in Mammoth Cave National Park (MCNP), are energy-poor. The major food base is fincly triturated and larger organic debris washed into the cave ecosystem (Barr and Kuehne, 1971) augmented by cricket guano, eggs and carcasses (Poulson and Culver, 1969). These caves contrast markedly with the energy-rich caves occupied by large bat or bird colonies (see Howarth, 1983).

To provide initial baseline data necessary to quantify input of fixed energy by trogloxenes, we have begun studies of energetics of cave crickels (Hadenoecus subterraneus) (Studier et al., 1986a) and water balance of cave and camel crickets (Studier et al., 1986b). The present study concerns the energy budget of camel crickets (Ceuthophilus stygius).

\section{MATERIALS AND METHODS}

Studies were conducted during the last week of June 1985 in Great Onyx Cave in MCNP, Ky. The potential relationship of hind femur length (HFL) to crop-free live weight (CFLW) was investigated as previously described (Studier $e$ al., 1986a). In addition to HFL and CFLW, data were obtained on fresh and dry weights of crop contents and enlarged reproductive tracts as well as crop-free dry weight for camel crickets of both sexes.

A long term weight luss study was begun at $0600 \mathrm{hr}$ local time on 22 June 1985 (designated time $=6 \mathrm{hr})$. Sixteen $(8$ male and 8 female) large $(\mathrm{HFL}>19.0 \mathrm{~mm})$ camel crickets with apparently full crops were collected just inside the entrance to Great Onyx Cave. These camel crickets were all penultimate instars (T. H. Hubbell, personal communication). Weighings were then begun and periodically continued as previously described (Studier et al., 1986a) until $1900 \mathrm{hr}$ local time on 27 June 1985 (designated time $=139 \mathrm{hr}$ ). Temperature and relative humidity were recorded periodically throughout the study (Certified Hygrometer and Temperature Indicator, Model HTAB-176, Abbeon Cal. Inc. Santa Barbara, Calif.). After the last weighings, crickets were killed and processed as previously

*Present address: Department of Health Behavior/ Education, School of Public Health, University of Michigan, Ann Arbor, MI 48109, USA. described. All accumulated, combined wastes produced by these caged crickets throughout the entire experiment were collected, dried and weighed.

Crop contents, carcasses, and combined wastes were burned in a Parr Oxygen Bomb Calorimeter (Moline, Illinois) to determine energy content.

\section{RESULTS}

The relationships of CFLW to HFL in female and male $C$. stygius arc highly significant $(F-36.77 ; 1$ and 24 d.f.; $P<0.0001 ; r^{2}=0.605$; and, $F=82.05$; 1 and 24 d.f.; $P<0.0001 ; r^{2}=0.774$, respectively), are shown in Fig. 1 and are expressed by the equations:

Female CFLW $(\mathrm{g})=0.1040 \mathrm{HFL}(\mathrm{mm})-1.114$

$$
( \pm 0.0171) \quad( \pm 0.328)
$$

and

$$
\begin{array}{r}
\text { Male CFLW (g)= } \\
\begin{aligned}
& 0.1151 \mathrm{HFL}(\mathrm{mm})-1.176 \\
&( \pm 0.0127) \quad( \pm 0.247), \\
& \text { M: CFLW }=0.1151 \mathrm{HFL}-1.176 \\
& \text { F: CFLW }=0.1040 \mathrm{HFL}-1.114
\end{aligned}
\end{array}
$$

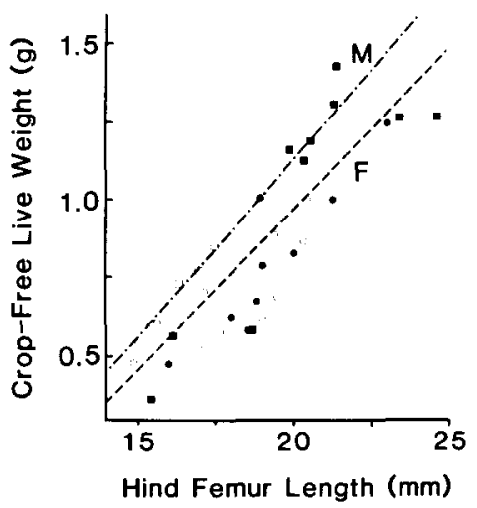

Fig. 1. The relationship of crop-free live weight (CFLW) to hind femur length (HFL) in Ceuthophilus stygius. Circles represent females and squares represent males. Filled symbols represent total weight of crickets wilh naturally empty crops. Open symbols represent carcass weight with crops dissected out. 


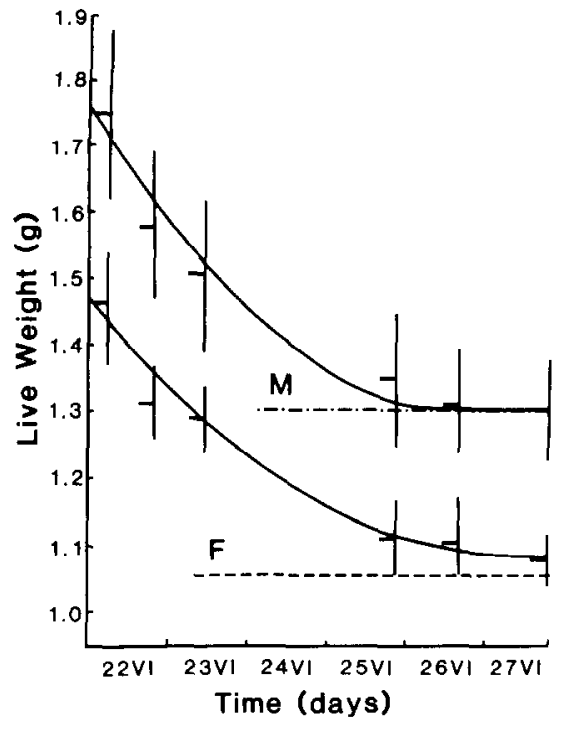

Fig. 2. Total live weight of caged large $C$. stygius over time. beginning with crop-full individuals. Symbols represent arithmetic mean and $95 \%$ confidence intervals. $M=$ males, $\mathrm{F}=$ females. Dashed lines represent CFLW of male and female camel crickets

respectively, where values in parentheses are the standard errors of the means. These relationships are unaffected by whether CFLW is measured for crickets with naturally empty crops or with crop contents removed.

Long-term weight losses of aged camel crickets are curvilinear and are illustrated in Fig. 2. Weight loss as a function of time for large (average HFL $=$ $20.5 \mathrm{~mm})$ males $(F=30.73,2$ and 45 d.f., $P<0.0001$, $\left.r^{2}=0.577\right)$ is expressed by:

$$
\begin{aligned}
& \text { Weight }(\mathrm{mg})=0.03493 \pm 0.01377(\text { time }=\mathrm{hr})^{2} \\
& -8.080+1.995(\text { time }=\mathrm{hr})+1766 \pm 50 .
\end{aligned}
$$

Weight loss over time for large (average $\mathrm{HFL}=19.7 \mathrm{~mm})$ females $(F=102.26,2$ and 45 d.f., $\left.P<0.0001, r^{2}=0.820\right)$ is expressed by:

$$
\begin{aligned}
& \text { Weight }(\mathrm{mg})=0.02350 \pm 0.00631(\text { time }=\mathrm{hr})^{2} \\
& -6.000 \pm 0.914(\text { time }=\mathrm{hr})+1472 \pm 23 .
\end{aligned}
$$

Also shown in Fig. 2 are the average CFLW for the male (M) and female (F) camel crickets studied
Table 1 gives caloric densities of camel cricket crop contents, and mixed wastes. In most cases it was necessary to pool crop contents from several individuals to obtain sufficient dry mass for bombing.

\section{DISCUSSION}

In our previous study of cave crickets (Studier $e t$ al., 1986a), we found a highly predictive, curvilinear relationship between CFLW and HFL. The present data show a linear, predictive relationship between those variables (Fig. 1) for camel crickets. The linear equations for $C$. stygius predict a minimal HFL of about $10.5 \mathrm{~mm}$ (at CFLW projected to 0). That suggestion is not supported by observation, since camel crickets with HFL smaller than $10.5 \mathrm{~mm}$ are seen earlier in the year. The true relation of HFL and CFLW in C. stygius is almost certainly curved as in $H$. subterraneus. Although an attempt was made in June to collect camel crickets of wide range of HFL, only one individual was found with HFL less than $15.0 \mathrm{~mm}$. Collections of $H$. subterraneus made in May, however, yielded relatively large numbers of individuals of HFL as short as $8.5 \mathrm{~mm}$. The seasonally restricted size range of camel crickets suggests highly coherent, seasonal reproductive patterns, while the much broader range of available sizes of cave crickets indicate reproductive effort which is less seasonally restricted.

Unlike cave crickets (Studier et al., 1986a), camel crickets (penultimate instars) of similar HFL have differing gender-related mass, e.g. in large crickets of $\mathrm{HFL}=20 \mathrm{~mm}$, male CFLW weight averages $1126 \mathrm{mg}$ while female CFLW average weight is $966 \mathrm{mg}$. This mass difference is also apparent in adult camel crickets. In October. the crops of roosting adult males are empty while adult female crops are not (Studier et al., 1986b). These cricket species and gender differences could relate to male territorial defense, courtship displays or polygynous reproductive habits among camel crickets. Camel crickets of either sex are much more massive than similarly sized cave crickets. Cave crickets of $20 \mathrm{~mm}$ HFL have an average CFLW of $352 \mathrm{mg}$, only about one-third of that of camel crickets of the same HFL (Studier et al., 1986a). This observation provides mild support to the generalization (sce Culver, 1982) that highly caveadapted animals have longer appendages and a gen-

\begin{tabular}{|c|c|c|c|}
\hline & E & calig total dry wt & cal/g total wet \\
\hline $\operatorname{crop}(\mathrm{B})$ & 5 & $4475 \pm 135$ & $1342 \pm 40$ \\
\hline wastes & 7 & $3760 \pm 66$ & ------ \\
\hline $\operatorname{carcass}(F)$ & 7 & $50: 0 \pm 74$ & $1308 \pm 19$ \\
\hline $\operatorname{carcass}(M)$ & 5 & $5388 \pm 73$ & $1407 \pm 19$ \\
\hline
\end{tabular}

Table 1. Caloric density of large $(H F L>19.0 \mathrm{~mm})$ camel cricket crop contents carcasses, and wastes. Values are mean and standard error of the mean; $F=$ female; $\mathbf{M}=$ male; $\mathbf{B}=$ both 
Table 2. Energetic parameters for large (HFL $>19.0 \mathrm{~mm}$ ) camel crickets, Ceuthophilus stygius. Values shown are mean and standard error of the mean. Units are mg unless otherwise indicated; $N=8$ for each sex: ${ }^{*}=P<0.055^{* *}=P<0.01$

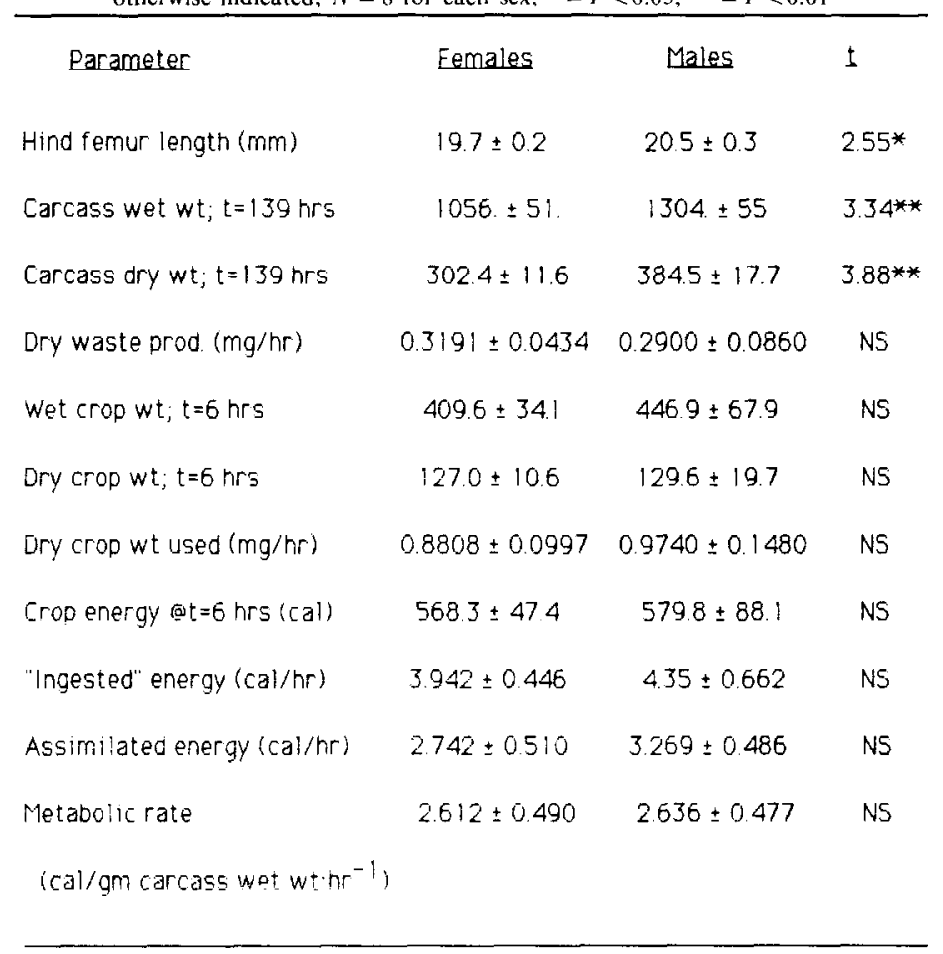

erally more fragile appearance than less cave-adapted animals.

Unlike the data for cave crickets (Studier et al., 1986a), average wet crop contents of large, fed female camel crickets $(410 \mathrm{mg}=38.9 \% \mathrm{CFLW})$ at the start of the weight loss experiment are not different from values for males $(447 \mathrm{mg}=34.4 \% \mathrm{CFLW}$ ) as seen in Table 2 . Table 3 summarizes the potential individual fixed energy cave input by male and female cave and camel crickets. The absolute crop biomass and potential fixed calories introduced to caves per foraging bout, are similar in both sexes of both species except for somewhat lower values for male $H$. subterraneus. In terms of weight specific crop biomass (my/my CFLW) and calories (cal/mg CFLW), individual cave crickets bring considerably more fixed energy into cave ecosystems per foraging bout than do camel crickets. Since the latter are estimated to forage much more frequently than cave crickets, however, potential energy delivered daily to cave ecosystems by large camel crickets may markedly exceed input by individual cave crickets. Lack of significant data on seasonal

Table 3. Foraging parameters in large cave crickets ( $H$. subterraneus) and large camel crickets (C. stygius). Data for cave crickets from Studier et al. (1986a). F = female; $\mathrm{M}=$ male

\begin{tabular}{|c|c|c|c|c|}
\hline \multirow[b]{2}{*}{ Parameter } & \multicolumn{2}{|c|}{ H. subterraneus } & \multicolumn{2}{|c|}{ C. styoius } \\
\hline & $E$ & $\Delta$ & $E$ & $\square$ \\
\hline Full crop (mg) & 428 & 284. & 410 & 447. \\
\hline Full crop (cal) & 474.0 & 326.0 & 568.3 & 580.0 \\
\hline$C F L W(m g)$ & 422 & 390. & 1055 & 1304 \\
\hline Full crop (mg/mg CFLW) & 1.004 & 0.720 & 0.389 & 0.343 \\
\hline Full crop (cal/mg CFLW) & 1.123 & 0.836 & 0.539 & 0.445 \\
\hline Foraging interval(days) & 11.5 & 9.9 & 3.0 & 23 \\
\hline Forage rate (mg/day) & 37.2 & 28.4 & 136.7 & 194.3 \\
\hline
\end{tabular}


population sizes or size distribution data preclude further quantitative projection of potential energy input by either cricket species.

As outlined earlier for cave crickets (Studier et al., 1986a), long term weight loss in fed crickets can be used to estimate maximum foraging intervals if CFLW of crickets is also known. In cave crickets, the long term weight loss pattern was linear and projected to maximum foraging intervals of 11.5 and 9.9 days for females and males, respectively. The weight loss pattern of fed camel crickets is curvilinear (Fig. 2) and, therefore, does not lend itself to easy or accurate estimation of maximal foraging intervals. We interpret the rapid early weight loss to represent the rate of crop biomass usage during the first few days after feeding, while the much slower weight loss occurring on days $4-6$ is interpreted to represent, not crop biomass usage, but utilization by camel crickets of stored energy in the form of fats or glycogen. Rate of weight loss during the first 2 days $(5.69 \mathrm{mg} / \mathrm{hr}$ and $7.99 \mathrm{mg} / \mathrm{hr}$, for females and males, respectively) was used to estimate time interval for crop emptying and foraging intervals (Table 3 ) of 3.0 and 2.3 days for females and males, respectively.

Energetic parameters for large camel crickets, given in Table 2, are based upon patterns over the entire long-term weight loss study. As just discussed, values in Table 2 underestimate actual energetic parameters during the first 2 days and overestimate those levels during the last 2 days. Calculation of entries in Table 2 requires data from Tables 1 and 4 and is explained in our previous paper (Studier et al., 1986a). There are no gender related differences in energetic parameters in $C$. stygius except for carcass biomass differences already discussed. With the exception of estimated metabolic rates, there are also no differences in energetic parameters of $C$. stygius (Table 2) and cave crickets (Table 2, Studier et al., 1986a) which cannot be readily attributed to biomass differences in the two species. Estimated metabolic rates (cal/gm CFLW/hr) of female $(2.61 \pm 0.49)$ and male $(2.64 \pm 0.48)$ camel crickets are not significantly different from expected rates for insects of similar biomass (3.29 and 3.04, for females and males, respectively; Kayser and Heusner, 1964). Cave crickets, however, show metabolic rates which are markedly lower than expected (Studier et al., 1986a). Low metabolic rates appear to be characteristic of cavernicolous as opposed to epigean species (Poulson and White, 1969; Culver, 1982). C. stygius may, therefore, not be as cave adapted as $H$. subterraneus.

Regarding measured caloric levels (Table 1) of large camel crickets, male carcass caloric density is significantly higher than in females $(t=3.63$; d.f. $=$ $10 ; P<0.01$ ). In comparing camel crickets (Table 1) with cave crickets (Studier et al., 1986a), there are no differences in female carcass caloric density; however, carcass caloric density of male camel crickets exceeds that of male cave crickets $(t=4.45 ;$ d.f. $=10$; $P<0.01)$. In general, differences in dry caloric density when values are near to or exceed $5.0 \mathrm{Kcal} / \mathrm{g}$, are attributed to differences in lipid levels. Our data indicated a greater level of stored lipid in large male C. stygius compared to females of the same species or to cave crickets of either sex.

There is a great difference in caloric density of mixed wastes between the two species $(t=11.11$; d.f. $=12 ; P<0.001)$. The extremely low caloric density of mixed wastes of cave crickets has been previously discussed (Studier et al., 1986a). The higher caloric density of camel crickets wastes may reflect a lesser contribution of microbial fermentation to digestive characteristics of camel crickets or reduced efficiency of assimilation.

The markedly lower mixed waste caloric content of cave crickets contributes significantly to the generally greater assimilation efficiencies of both dry matter and, especially, calories of cave crickets (Studier et al., 1986a) in comparison to camel crickets (Table 4). Dry matter assimilition efficiency in camel crickets compares favorably with values for house crickets (Woodring et al., 1979) as well as other insects (Slansky and Scriber, 1984).

Contributions of guano from each species to the energy base in the cave is affected by caloric value of wastes, amount of wastes, and frequency of feeding,

Tahle 4 Per cent water and ner cent assimilation efficiency of large camel crickets, Ceuthophilus stygius. $N=8$ for each sex

\begin{tabular}{lcc} 
Parameter & Female & Male \\
& \multicolumn{2}{c}{ Percent water } \\
crop, day 0 & 69.0 & 71.0 \\
carcass, day 0 & 76.4 & 72.7 \\
carcass, day 5 & 71.4 & 70.5 \\
& & \\
& Bercent.Assimilation Efficiency. \\
dry matter & 68.0 & 72.2 \\
calories & 65.6 & 70.5
\end{tabular}


suggesting that $C$. stygius may be an important source of imported detrital food compared to $H$. subterraneus. Seasonal differences in sizes of individuals making up the populations of $C$. stygius compared to the more consistent size distribution of $H$. subterraneus, however, may off-set some of the differences on a year-round basis. Distribution of the two species within a cave is also different, with camel crickets typically found close to cave entrances and cave crickets more widely distributed. Energy inputs from cave cricket guano, although low, are predictable, and are probably more important to the troglobitic animals deep within a cave than camel cricket guano.

Acknowledgements - We would like to thank the many people who gave generously of their time, effort, and ideas during the field work, especially Ann Studier and Terry Bellis. Ellen Levy offered insights into cave cricket biology. Dr Tom Poulson, Dr Mike Martin, and Dr T. H. Hubbell read drafts of the manuscript and offered useful comments. We would like to thank the National Park Service and its personnel for providing access to the cave, and the Cave Research Foundation for the use of its facilities in Mammoth Cave National Park.

This research was done in support of NPS MACA-N-103.

\section{REFERENCES}

Barr T. C. Jr. and Kuehne R. A. (1971) Ecological studies in the Mammoth Cave system of Kentucky, I. Biota. Int. J. Speleol. 3, 147-204.

Culver D. C. (1982) Cave Life; Evolution and Ecology, Vol. IX. Harvard Univ. Press, Cambridge, Massachusetts.

Howarth F. G. (1983) Ecology of cave arthropods. A. Rev. Ent. 28, 365-389.

Kayser C. and Heusner A. (1964) Etude comparative du metabolisme energetique dans la serie animale. J. Phys. iol., Paris 56, 489-524.

Poulson T. L. and Culver D. C. (1969) Diversity in terrestrial cave communities. Ecology 50, 153-158.

Poulson T. L. and White W. B. (1969) The cave environment. Science $165,971-981$.

Slansky F. Jr. and Scriber J. M. (1984) Food consumption and utilization. In Comprehensive Insect Physiology, Biochemistry, and Pharmacology (Edited by Kerkut G. A. and Gilbert L. J.), Vol. 4, pp. 87-163. Pergamon Press, Oxford.

Studier E. H., Lavoie K. II., Wares W. D. II, and Linn J. A. M. (1986a) Bioenergetics of the cave cricket, Hadenoecus subterraneus. Comp. Biochem. Physiol. A 84A, 431-436.

Studier E. H., Wares W. D. II, Lavoie K. H. and Linn J. A. M. (1986b) Water budgets of cave crickets, Hadenoecus subterraneus, and camel crickets, Ceuthophilus stygius. Comp. Biochem. Physiol. A 86A, 97-102.

Woodring J. P., Clifford C. W. and Beckman B. R. (1979) Food utilization and metabolic efficiency in larval and adult house crickets. J. Insect Physiol. 25, 903-912. 